\title{
Age as an independent factor for the development of neuropathy in diabetic patients
}

\author{
This article was published in the following Dove Press journal: \\ Clinical Interventions in Aging \\ 15 March 2016 \\ Number of times this article has been viewed
}

\author{
Simona Popescu ${ }^{1,2}$ \\ Bogdan Timar ${ }^{2,3}$ \\ Flavia Baderca ${ }^{4,5}$ \\ Mihaela Simu ${ }^{6,7}$ \\ Laura Diaconu ${ }^{1,2}$ \\ Iulian Velea ${ }^{8,9}$ \\ Romulus Timar ${ }^{1,2}$
}

'2nd Department of Internal

Medicine, "Victor Babes" University of Medicine and Pharmacy, ${ }^{2}$ Clinic of Diabetes, Nutrition and Metabolic Diseases, Emergency Clinical County Hospital, ${ }^{3}$ Department of Functional Sciences, ${ }^{4}$ Department of Microscopic Morphology, "Victor Babes" University of Medicine and Pharmacy, ${ }^{5}$ Service of Pathology, Emergency City Hospital, ${ }^{6}$ Department of Neurosciences, "Victor Babes" University of Medicine and Pharmacy, ${ }^{7}$ Clinic of Neurology, Emergency Clinical County Hospital, ${ }^{8}$ Department of Pediatrics, "Victor Babes" University of Medicine and Pharmacy, ${ }^{9} \mathrm{Clinic}$ of Pediatrics, Emergency Clinical County Hospital, Timisoara, Romania

\begin{abstract}
Population aging is unprecedented, without parallel in the history of humanity. As type 2 diabetes mellitus is predominantly more prevalent in aging populations, this creates a major public health burden. Older adults with diabetes have the highest rates of major lowerextremity amputation, myocardial infarction, visual impairment, and end-stage renal disease of any age group. The aims of our study were to assess whether age is an independent factor for the occurrence of diabetic neuropathy (DN), and to evaluate the relationship between the presence and the severity of DN and the diabetes duration and blood glucose level. In this study, we enrolled 198 patients, previously diagnosed with type 2 diabetes mellitus. For all patients, we measured hemoglobin $\mathrm{A}_{1 \mathrm{c}}\left(\mathrm{HbA}_{1 \mathrm{c}}\right)$, lipid profile, and body mass index and we assessed the presence and severity of DN using the evaluation of clinical signs and symptoms. Patients had a median age of 62 years, with a median of diabetes duration of 7 years; $55.1 \%$ of the patients were men and the average $\mathrm{HbA}_{1 \mathrm{c}}$ in the cohort was $8.2 \%$. The prevalence of DN according to Michigan Neuropathy Screening Instrument was $28.8 \%$, being significantly and positively correlated with higher age ( 65 vs 59 years; $P=0.001$ ) and $\mathrm{HbA}_{1 \mathrm{c}}(8.6 \%$ vs $8.0 \% ; P=0.027$ ). No significant correlations were observed between the severity of DN and diabetes duration, body mass index ( 31.9 vs $29.9 \mathrm{~kg} / \mathrm{m}^{2}$ ), or the number of centimeters exceeding the normal waist circumference ( $25.2 \mathrm{vs} 17.3 \mathrm{~cm} ; P=0.003$ ). In conclusion, age influences the presence of DN, independent on other risk factors. This influence persists even after adjusting for other, very important risk factors, like blood glucose level or diabetes duration.
\end{abstract}

Keywords: peripheral neuropathy, elderly patients, type 2 diabetes mellitus, body mass index, hemoglobin $\mathrm{A}_{1 \mathrm{c}}$, diabetic neuropathy

\section{Introduction}

As a consequence of population's demographical changes, we are witnessing an increase in the proportion of persons of 60 years or older in parallel with a decline in the proportion of the young, such that by 2050 it is expected that the proportion of elderly persons will have risen from $15 \%$ (which is today's ratio) up to $25 \%{ }^{1}$

This demographic shift will have a direct impact on the epidemiology of chronic, nontransmissible diseases, including type 2 diabetes mellitus (T2DM). Nowadays, the prevalence of T2DM is approximated at 382 million cases, being expected to affect 592 million people by 2035. As T2DM is predominantly more prevalent in aging population, this premise is creating a major public health burden. ${ }^{1}$

More than $25 \%$ of the US population aged $\geq 65$ years has diabetes, ${ }^{2}$ and the aging of the overall population is a significant driver of the diabetes epidemic. Although the burden of diabetes is often described in terms of its impact on working-age adults, diabetes in older adults is linked to higher mortality, reduced functional status, and increased risk of institutionalization. ${ }^{3}$ Older adults with diabetes are at substantial risk for both acute and
Department of Functional Sciences,

"Victor Babes" University of Medicine and Pharmacy, 2 Eftimie Murgu, 30004I,

Timisoara, Romania

Tel +40246 74I 528093

Email timar.bogdan@umft.ro (c) (1) (2) 2016 Popescu et al. This work is published and licensed by Dove Medical Press Limited. The full terms of this license are available at https://www.dovepress.com/terms.php BY NC and incorporate the Creative Commons Attribution - Non Commercial (unported, v3.0) License (http:///creativecommons.org/licenses/by-nc/3.0/). By accessing the work you
hereby accept the Terms. Non-commercial uses of the work are permitted without any further permission from Dove Medical Press Limited, provided the work is properly attributed. For permission hereby accept the Terms. Non-commercial uses of the work are permitted without any further permission from Dove Medict
for commercial use of this work, please see paragraphs 4.2 and 5 of our Terms (https://www.dovepress.com/terms.php). 
chronic microvascular and cardiovascular complications of the disease. Diabetic neuropathies (DN) encompass a wide range of nerve abnormalities and are common, with prevalence rates reported between 5\% and $100 \%$ depending on the diagnostic criteria. ${ }^{4-6}$ Distal symmetric polyneuropathy is the most common form of DN. ${ }^{7}$ The duration and severity of hyperglycemia, presence of dyslipidemia, hypertension, and smoking are major risk factors for the development of diabetic polyneuropathy. ${ }^{8}$

The aims of our study were to assess whether age is an independent factor for the occurrence of DN, and to evaluate the relationship between the presence and the severity of DN and the diabetes duration and blood glucose level.

\section{Materials and methods Study design and patients}

In this cross-sectional, noninterventional study, we enrolled 198 patients, previously diagnosed with T2DM, attending scheduled visits at the outpatient facility of the Emergency Hospital Timisoara between May 1, 2013 and June 30, 2014. Patients were enrolled according to a consecutive population principle, after signing an informed consent form. Since this is a noninterventional, cross-sectional study, according to the local protocols, this had to be approved only by the local Ethics Committee. The Ethics Committee of the Emergency Hospital Timisoara granted the approval number 266/2012. The following were exclusion criteria in the study protocol: inability to provide informed consent, inability to provide accurate anamnestic medical history data, prior history of non-DN (ie, alcoholic neuropathies), major cardiovascular events (according to Hicks 2014 criteria) 3 months prior to screening, or any other condition which, in the investigators' opinion, could lead to biases in the study results.

For all patients, we measured hemoglobin $\mathrm{A}_{1 \mathrm{c}}\left(\mathrm{HbA}_{1 \mathrm{c}}\right)$, lipid profile, and body mass index (BMI) and we assessed the presence and severity of DN using the evaluation of clinical symptoms. Also, for all patients, we measured the waist circumference values; we considered normal for men $<94 \mathrm{~cm}$ and for women $<80 \mathrm{~cm}$. The presence and severity of chronic kidney disease was diagnosed according to Kidney Disease: Improving Global Outcomes 2012 guidelines. Retinopathy diagnosis was established after performing a funduscopic examination by the same trained ophthalmologist, specialized in the diagnosis and treatment of diabetic eye complications. ${ }^{9}$ Hypertension was defined as resting blood pressure $>140 \mathrm{mmHg}$ (systolic) and/or $>90 \mathrm{mmHg}$ (diastolic); autonomic neuropathy was assessed using the presence of orthostatic hypotension, defined as a fall in blood pressure in response to postural changes $(>20 \mathrm{mmHg}$ for systolic or $>10 \mathrm{mmHg}$ for diastolic blood pressure). Michigan Neuropathy Screening Instrument (MNSI) is a score instrument designed for diagnosis and severity evaluation of $\mathrm{DN}$, which contains a patient's symptoms questionnaire and clinical assessment tool. We considered positive for overt neuropathy the presence of one out of the following criteria: a global score $\geq 9.5$, questionnaire score $\geq 7$, or clinical score $\geq 2.5$. A higher score is associated with more severe neuropathy.

\section{Statistical analysis}

Data were collected and analyzed using SPSS version 17 statistical software package (SPSS Inc., Chicago, IL, USA) and were presented as average \pm standard deviation (numerical variables with Gaussian distribution), median, and interquartile range (numerical variables with nonparametric distributions), respectively percentage from the subgroup total and (number of individuals) for categorical variables. To assess the significance of the differences between groups, the Student's $t$-test (means, Gaussian populations), MannWhitney $U$-test (medians, nonparametric populations), and chi-square test (proportions) were used. Continuous variables distributions were tested for normality using Shapiro-Wilk test, and for equality of variances using Levene's test.

To evaluate the strength of the association between two continuous variables, we used Spearman's correlation coefficient; the statistical significance of the correlation was evaluated using $t$-distribution test. The individual impact of several confounding factors on the variance of a continuous variable was assessed by building multivariate regression models or if the dependent variable was dichotomous by building multivariate logistic regressions. The predictors, in the final regression equations, were accepted according to a repeated backward-stepwise algorithm (inclusion criteria $P<0.05$, exclusion criteria $P>0.10$ ) in order to obtain the most appropriate theoretical model to fit the collected data. The quality of the model was described using the accuracy of the prediction by adjusted $R^{2}$ (multivariate linear regression) and Nagelkerke's $R^{2}$ (logistic regression).

In this study, a $P$-value of 0.05 was considered the threshold for statistical significance.

\section{Results}

Patients had a median age of 62 years, with a median of diabetes duration of 7 years; $55.1 \%$ of the patients were men and the average $\mathrm{HbA}_{1 \mathrm{c}}$ in the cohort was $8.2 \%$. The detailed characteristics of the study cohort are presented in Table 1.

In our studied group, the prevalence of DN according to MNSI score was 28.8\% (57 individuals). 
Table I Studied group baseline characteristics

\begin{tabular}{|c|c|}
\hline Age (years) ${ }^{\mathrm{a}}$ & $62(11)$ \\
\hline Diabetes mellitus duration (years) ${ }^{\mathrm{a}}$ & $7(8)$ \\
\hline $\mathrm{HbA}_{\mathrm{Ic}}(\%)^{\mathrm{b}}$ & $8.2 \pm 1.7$ \\
\hline BMI $\left(\mathrm{kg} / \mathrm{m}^{2}\right)^{\mathrm{b}}$ & $30.5 \pm 4.3$ \\
\hline Waist circumference exceed $(\mathrm{cm})^{\mathrm{b}}$ & $19.6 \pm 16.9$ \\
\hline Total cholesterol $(\mathrm{mg} / \mathrm{dL})^{\mathrm{b}}$ & $203.3 \pm 57.7$ \\
\hline $\mathrm{HDL}$ cholesterol $(\mathrm{mg} / \mathrm{dL})^{\mathrm{b}}$ & $45.4 \pm 10.6$ \\
\hline LDL cholesterol $(\mathrm{mg} / \mathrm{dL})^{\mathrm{b}}$ & $|22.9 \pm 45|$. \\
\hline Triglycerides $(\mathrm{mg} / \mathrm{dL})^{\mathrm{b}}$ & $176.2 \pm 83.1$ \\
\hline Male sex ${ }^{c}$ & $55.1 \%(109)$ \\
\hline Hypertension ${ }^{c}$ & $81.8 \%(162)$ \\
\hline Smokers ${ }^{c}$ & $32.8 \%(65)$ \\
\hline Alcohol consumption ${ }^{c}$ & $19.7 \%(39)$ \\
\hline Chronic kidney disease $^{c}$ & $26.3 \%(52)$ \\
\hline Retinopathyc & $31.3 \%(62)$ \\
\hline
\end{tabular}

Notes: ${ }^{a}$ Numerical variables with non-Gaussian distribution. Results are presented as median (interquartile range). ' Numerical variables with Gaussian distribution. Results are presented as average \pm standard deviation. 'Dichotomous variables. Results are presented as percentage from total (number of individuals).

Abbreviations: $\mathrm{BMI}$, body mass index; $\mathrm{HbA}_{\mathrm{Ic}}$, hemoglobin $\mathrm{A}_{\mathrm{Ic}}$; $\mathrm{HDL}$, high-density lipoprotein; LDL, low-density lipoprotein.

The presence of DN was associated with higher age (65 vs 59 years; $P=0.001$ ), $\mathrm{HbA}_{1 \mathrm{c}}$ ( 8.6 vs $8.0 \% ; P=0.027$ ), BMI (31.9 vs $\left.29.9 \mathrm{~kg} / \mathrm{m}^{2}\right)$, and with more accentuated exceed in waist circumference ( 25.2 vs $17.3 \mathrm{~cm} ; P=0.003$ ). Regarding the other studied parameters, we observed no significant differences with respect to the presence or absence of DN (Table 2).

Regarding the complications and comorbidities most commonly associated with T2DM, we observed a significantly higher prevalence in patients having $\mathrm{DN}$ for chronic kidney disease $(56.1 \%$ vs $14.2 \% ; P<0.001)$, retinopathy (54.4\% vs $22.0 \% ; P<0.001)$, and for autonomic neuropathy (52.6\% vs $8.5 \% ; P<0.001)$. No significant differences were observed for the prevalence of hypertension in the two studied subgroups (Table 3 ).
To evaluate the factors involved in the development of DN in diabetic patients, we built a backward-stepwise multivariate logistic regression model, having as dependent variable the positive diagnosis of DN and the initial predictors: patient's age, diabetes duration, $\mathrm{HbA}_{1 \mathrm{c}}$ value, sex, and BMI. The following three consecutive selection steps (having the exclusion criteria $P>0.100$ ) in the final regression equation were accepted as significant predictors for the development of DN: patient's age, diabetes duration, and the BMI. The created model explained $17.3 \%$ of causality due to $\mathrm{DN}$, the theoretical regression equation having $74.7 \%$ accuracy when compared with the collected data. According to our model, for every advance of 1 year in patient's age, the odds for developing DN increased by $11.2 \%(P<0.001)$ and for each increase of $1 \mathrm{~kg} / \mathrm{m}^{2}$ in patient's BMI, the odds for developing DN increased by $10.9 \%(P=0.012)$.

In our study, the severity of DN, assessed using the MNSI global score, was significantly and positively correlated with age ( $r=0.344 ; P<0.001$; Figure 1$)$ and with the $\mathrm{HbA}_{\mathrm{lc}}$ value $(r=0.380 ; P<0.001)$. No significant correlations were observed between the severity of DN and diabetes duration (Figure 2), BMI, or the number of centimeters exceeding the normal waist circumference.

To assess the independent impact (and not only as cofactors) on the severity of DN, we built a backwardstepwise multivariate regression model, having as dependent variable the DN severity and as initial predictors: patient's age, diabetes duration, $\mathrm{HbA}_{1 \mathrm{c}}$ value, and BMI. Our regression equation proved to be a good fit for the model, explaining $28.6 \%$ of the DN severity variations $\left(R^{2}=0.286\right)$. The model revealed a significant impact, as independent predictors, for patient's age $(P<0.001)$, diabetes duration $(P=0.004)$, and $\mathrm{HbA}_{1 \mathrm{c}}$ value $(P<0.001)$, while BMI was only marginally significant $(P=0.081)$. Our model suggests that for one standard

Table 2 Comparison of studied parameters for patients with and without DN

\begin{tabular}{|c|c|c|c|}
\hline & DN absent $(n=|4|)$ & DN present $(n=57)$ & $P$-value \\
\hline Age (years) ${ }^{\mathrm{a}}$ & $59(12)$ & $65(10)$ & 0.001 \\
\hline Diabetes mellitus duration (years) ${ }^{\mathrm{a}}$ & $7(9)$ & 7 (7) & 0.867 \\
\hline $\mathrm{HbA}_{\mathrm{Ic}}(\%)^{\mathrm{b}}$ & $8.0 \pm 1.8$ & $8.6 \pm 1.6$ & $0.027^{*}$ \\
\hline BMI $\left(\mathrm{kg} / \mathrm{m}^{2}\right)^{\mathrm{b}}$ & $29.9 \pm 4.3$ & $31.9 \pm 3.9$ & $0.003 *$ \\
\hline Waist circumference exceed $(\mathrm{cm})^{\mathrm{b}}$ & $17.3 \pm 16.9$ & $25.2 \pm 15.5$ & $0.003^{*}$ \\
\hline Total cholesterol $(\mathrm{mg} / \mathrm{dL})^{\mathrm{b}}$ & $205.2 \pm 58.1$ & $198.6 \pm 57.1$ & 0.469 \\
\hline HDL cholesterol $(\mathrm{mg} / \mathrm{dL})^{\mathrm{b}}$ & $45.2 \pm 10.4$ & $46.1 \pm 11.2$ & 0.587 \\
\hline LDL cholesterol $(\mathrm{mg} / \mathrm{dL})^{\mathrm{b}}$ & $123.6 \pm 47.1$ & $121.0 \pm 40.1$ & 0.713 \\
\hline Triglycerides $(\mathrm{mg} / \mathrm{dL})^{\mathrm{b}}$ & $179.4 \pm 87.5$ & $|68.4 \pm 7| .2$ & 0.403 \\
\hline
\end{tabular}

Notes: aNumerical variables with non-Gaussian distribution. Results are presented as median (interquartile range). P-value was calculated using Mann-Whitney U-test. 'Numerical variables with Gaussian distribution. Results are presented as average \pm standard deviation. $P$-value was calculated using unpaired Student's $t$-test. *Indicates statistical significance.

Abbreviations: BMI, body mass index; DN, diabetic neuropathy; $\mathrm{HbA}_{\mathrm{Ic}}$, hemoglobin $\mathrm{A}_{\mathrm{Ic}}$; $\mathrm{HDL}$, high-density lipoprotein; LDL, low-density lipoprotein. 
Table 3 Prevalence of complications and comorbidities in patients with and without DN

\begin{tabular}{llll}
\hline & $\begin{array}{l}\text { DN absent } \\
(\mathbf{n}=\mathbf{I 4 I})\end{array}$ & $\begin{array}{l}\text { DN present } \\
(\mathbf{n}=\mathbf{5 7})\end{array}$ & P-value \\
\hline Chronic kidney disease & $\mathrm{I} 4.2 \%(20)$ & $56.1 \%(32)$ & $<0.00 \mathrm{I}^{*}$ \\
Retinopathy & $22.0 \%(3 \mathrm{I})$ & $54.4 \%(3 \mathrm{I})$ & $<0.00 \mathrm{I}^{*}$ \\
Hypertension & $83.0 \%(\mathrm{II})$ & $78.9 \%(45)$ & 0.505 \\
Autonomic neuropathy & $8.5 \%(\mathrm{I})$ & $52.6 \%(30)$ & $<0.00 \mathrm{I}^{*}$ \\
\hline
\end{tabular}

Notes: *Indicates statistical significance. Results are presented as percentage from the subgroup's total (number of individuals). $P$-value was calculated with chi-square test.

Abbreviation: DN, diabetic neuropathy.

deviation increase in patient's age, we expect an increase in the DN severity of 0.43 standard deviations. The detailed results of the regression model are presented in Table 4.

\section{Discussion}

Older adults with diabetes have the highest rates of major lower-extremity amputation, ${ }^{10}$ myocardial infarction, visual impairment, and end-stage renal disease of any age group. Those aged $\geq 75$ years have higher rates than those aged 65-74 years for most complications. Deaths from hyperglycemic crises also are significantly higher in older adults. Those aged $\geq 75$ years also have double the rate of emergency department visits for hypoglycemia than the general population with diabetes. ${ }^{11}$

Peripheral neuropathies commonly affect older people. Peripheral neuropathy can be caused by axonal damage or demyelination, as well as damage to large or small fibers. In the US for 1999-2000, 28\% of adults aged 70-79 years and $35 \%$ of adults aged $\geq 80$ years had peripheral neuropathy based on a simple screen for reduced sensation at the foot. ${ }^{12}$

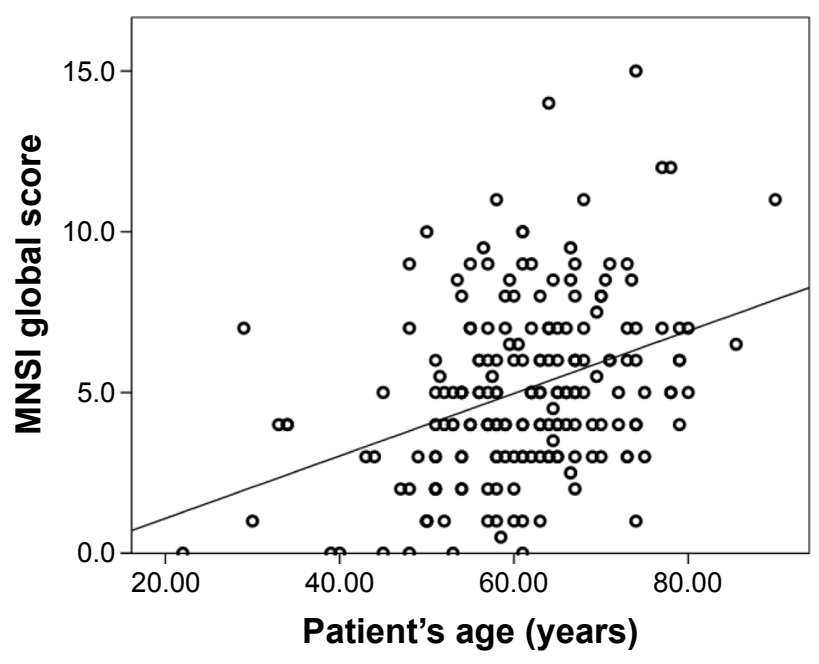

Figure I Correlation between patient's age and the MNSI score. Abbreviation: MNSI, Michigan Neuropathy Screening Instrument.

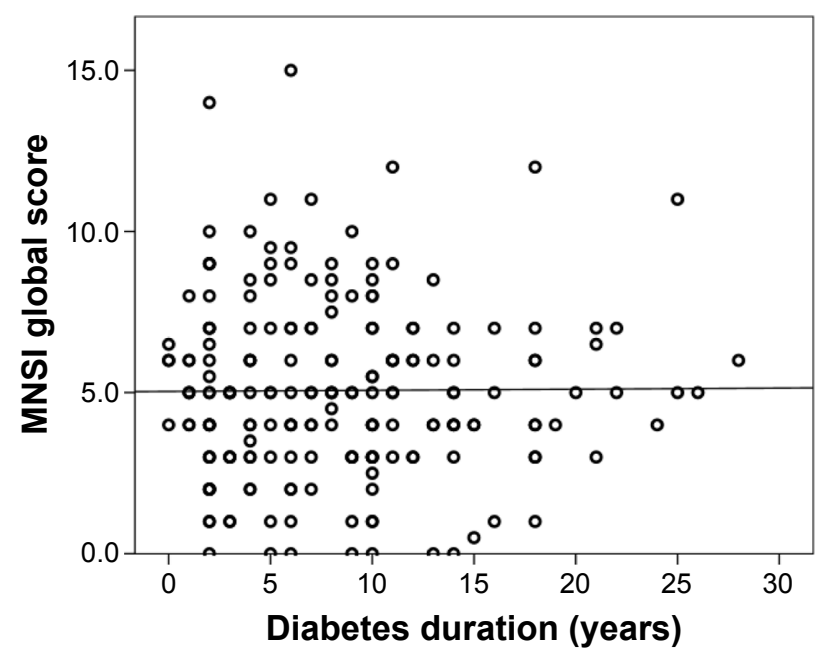

Figure 2 Correlation between diabetes duration and MNSI score. Abbreviation: MNSI, Michigan Neuropathy Screening Instrument.

The risk of falls and disabling symptoms like pain are quite pronounced in the elderly, leading to poor quality of life. Epidemiologic studies have found that older adults with poor peripheral nerve function have worse physical performance, balance, muscle density, and bone density. ${ }^{13-17}$

Diabetes and heavy alcohol use commonly cause symmetrical axonal polyneuropathies.

A twofold higher prospective decline in motor performance exists for older adults with distal symmetrical neuropathy. ${ }^{18}$

The studied group had a relatively poor glycemic and lipid control, having at the same time a moderate T2DM duration. These characteristics, representative of the local population of patients with T2DM, were not influenced by the investigators selection, thus we cannot add in the discussion a possible selection bias. The studied group baseline characteristics were a consequence of the population-based consecutive-case enrollment principle.

DNs are the most common forms of neuropathy, they account for more hospitalizations than all other diabetic complications combined, and are responsible for $50 \%-75 \%$ of nontraumatic amputations. ${ }^{19,20}$

Clinical consequences of higher fall and fracture rates are also evident in older adults with peripheral nerve impairments. In a prospective cohort aged $\geq 70$ years, those with loss of touch sensation in their feet had 2.5-times greater risk of major injurious falls, including fractures, joint dislocations, lacerations requiring sutures, and intracranial injuries..$^{21}$ In the Study of Osteoporotic Fractures, recurrent falling was related to worse vibration sense (age-adjusted odds ratio $=1.12,95 \%$ confidence interval: $1.05-1.19$ ) and 
Table 4 Multivariate regression model

\begin{tabular}{|c|c|c|c|c|c|}
\hline & \multicolumn{2}{|c|}{$\begin{array}{l}\text { Unstandardized } \\
\text { coefficients }\end{array}$} & \multirow{2}{*}{$\begin{array}{l}\text { Standardized } \\
\text { coefficients } \\
\text { Beta } \\
\end{array}$} & \multirow[t]{2}{*}{ Student's $t$-test } & \multirow[t]{2}{*}{$P$-value } \\
\hline & Beta & Standard error & & & \\
\hline Constant & -14.386 & 1.647 & & -8.734 & $<0.001$ \\
\hline Patient's age (years) & 0.114 & 0.019 & 0.430 & 5.936 & $<0.001$ \\
\hline Diabetes duration (years) & -0.095 & 0.033 & -0.207 & -2.901 & 0.004 \\
\hline $\mathrm{HbA}_{\mathrm{Ic}}(\%)$ & 0.509 & 0.097 & 0.322 & 5.265 & $<0.001$ \\
\hline BMI $\left(\mathrm{kg} / \mathrm{m}^{2}\right)$ & 0.070 & 0.040 & 0.109 & 1.753 & 0.081 \\
\hline
\end{tabular}

Note: Dependent variable: global MNSI score.

Abbreviations: BMI, body mass index; $\mathrm{HbA}_{1 \mathrm{c}}$, hemoglobin $\mathrm{A}_{\mathrm{Ic}}$; MNSI, Michigan Neuropathy Screening Instrument.

loss of touch sensation (age-adjusted odds ratio $=1.58,95 \%$ confidence interval: $1.34-1.87$ ) in older women. ${ }^{22}$

The management of diabetic polyneuropathy has three main elements: normal blood glucose level, foot care, and treatment of pain. Blood glucose level is the most important factor in the prevention and progression of DN. ${ }^{23}$ For optimal foot care, patients should be educated to inspect their feet on a daily basis to look for dry or cracking skin, fissures, plantar callus formation, and signs of early infection between the toes and around the toe nails. Fortunately, only a minority of patients with diabetic polyneuropathy will develop painful symptoms and sometimes pain symptoms may resolve spontaneously. In other cases, pain control may be achieved using one or more of the drugs.

Usually, there are no specific treatments available. A multidisciplinary approach with pain relief, physiotherapy, management of anxiety and depression are important in managing these patients.

According to our study, for every advance of 1 year in patient's age, the odds for developing DN increased by $11.2 \%$.

As in published literature, we found that DN is more common among elderly people and during its evolution is accompanied by an account of complications, which is why DN should be diagnosed and treated earlier. ${ }^{24}$ Like in other studies, we observed that the influence of age persists even after adjusting for other, very important risk factors, like glycemic control or diabetes duration. It is known that complications of T2DM are a consequence of a long-time poor glycemic control, this being the reason why in many studies the presence and severity of DN and other T2DM complications is described as being associated with a longer diabetes duration. ${ }^{25}$ However, if a good glycemic control is obtained during the entire course of DM, the probability of developing T2DM complications is similar to a nondiabetic one. After adjustments for glycemic control and other possible confounding factors in our study, we observed that diabetes duration is a significant predictor for DN only as a cofactor to others, having a nonsignificant influence when analyzed independently. This statement demonstrates furthermore that the advance in age acts in an independent manner in relation to the diabetes duration, being associated with an increased risk of developing DN; this is why, we agree that age is an independent factor for the development of $\mathrm{DN}$ in T2DM patients.

Regarding the limitations of this study, we identified that this study had a cross-sectional design and the T2DM complications developed during a long-time exposure to elevated blood-sugar levels. The quality of the glycemic control, measured using the $\mathrm{HbA}_{1 \mathrm{c}}$ value, can be evaluated for no longer than 3 months prior to the enrollment in the study. However, in many patients, a cross-sectional not-adequate glycemic control is associated with a prior history of deteriorated metabolic control, thus it may reflect the association between this parameter and the occurrence of T2DM chronic complications, including DN. Another limitation of the study is the use of the MNSI tool for the diagnosis of DN; MNSI is a validated screening tool for the diagnosis of $\mathrm{DN}$, however, it cannot be considered as a "gold standard" in the diagnosis and severity evaluation of DN.

The results of this study, demonstrating that advancing age is associated with an increased risk of developing DN in T2DM patients, emphasize the necessity of an intensified, proactive screening for DN in elderly patients with T2DM.

\section{Conclusion}

According to our study, the severity of DN was significantly and positively correlated with age and with the $\mathrm{HbA}_{1 c}$ value. No significant correlations were observed between the severity of DN and diabetes duration, BMI, or the number of centimeters exceeding the normal waist circumference. Age influenced the presence of DN, independent of other risk factors. 


\section{Disclosure}

The authors report no conflicts of interest in this work.

\section{References}

1. International Diabetes Federation. Global Guideline for Managing Older People with Type 2 Diabetes. Belgium: International Diabetes Federation; 2013:6-7.

2. Centers for Disease Control and Prevention. National Diabetes Fact Sheet: General Information and National Estimates on Diabetes in the United States. Atlanta, GA: US Department of Health and Human Services; 2011.

3. Brown AF, Mangione CM, Saliba D, Sarkisian CA; California Healthcare Foundation/American Geriatrics Society Panel on Improving Care for Elders with Diabetes. Guidelines for improving the care of the older person with diabetes mellitus. J Am Geriatr Soc. 2003;51(Suppl Guidelines):S265-S280.

4. Vinik AI, Mitchell BD, Leichter SB, Wagner AL, O'Brian JT, Georges LP. Epidemiology of the complications of diabetes. In: Leslie RDG, Robbins DC, editors. Diabetes: Clinical Science in Practice. Cambridge, UK: Cambridge University Press; 1995:221-287.

5. Knuiman M, Welborn T, McCann V, Stanton K, Constable I. Prevalence of diabetic complications in relation to risk factors. Diabetes. 1986;35:1332-1339.

6. Young MJ, Boulton AJ, MacLeod AF, Williams DR, Sonksen PH. A multicenter study of the prevalence of diabetic peripheral neuropathy in the United Kingdom hospital clinic population. Diabetologia. 1993;36:1-5.

7. Watkins PJ, Thomas PK. Diabetes mellitus and the nervous system. J Neurol Neurosurg Psychiatry. 1998;65(5):620-632.

8. Siyum S, Pippa M. Peripheral neuropathy in older people. GM. 2012; $42: 47-52$

9. Stevens PE, Levin A. Kidney Disease: Improving Global Outcomes Lipid Guideline Development Work Group Members. Evaluation and management of chronic kidney disease: synopsis of the kidney disease: improving global outcomes 2012 clinical practice guideline. Ann Intern Med. 2013;158(11):825-830.

10. Li Y, Burrows NR, Gregg EW, Albright A, Geiss LS. Declining rates of hospitalization for nontraumatic lower extremity amputation in the diabetic population aged 40 years or older: U.S., 1988-2008. Diabetes Care. 2012;35:273-277.

11. Centers for Disease Control and Prevention. Diabetes Public Health Resource. Available from: www.cdc.gov/diabetes. Accessed December 17, 2015.
12. Gregg EW, Sorlie P, Paulose-Ram R, et al. Prevalence of lowerextremity disease in the US adult population $\geq 40$ years of age with and without diabetes: 1999-2000 National Health and Nutrition Examination Survey. Diabetes Care. 2004;27:1591-1597.

13. Ford ES. Body mass index, diabetes, and C-reactive protein among U.S. adults. Diabetes Care. 1999;22:1971-1977.

14. Festa A, D'Agostino R Jr, Howard G, Mykkanen L, Tracy RP, Haffner SM. Chronic subclinical inflammation as part of the insulin resistance syndrome: the Insulin Resistance Atherosclerosis Study (IRAS). Circulation. 2000;102:42-47.

15. Resnick HE, Stansberry KB, Harris TB, et al. Diabetes, peripheral neuropathy, and old age disability. Muscle Nerve. 2002;25:43-50.

16. Strotmeyer ES, Cauley JA, Schwartz AV, et al. Reduced peripheral nerve function is related to lower hip BMD and calcaneal QUS in older white and black adults: the Health, Aging, and Body Composition Study. J Bone Miner Res. 2006;21:1803-1810.

17. Lauretani F, Bandinelli S, Bartali B. Axonal degeneration affects muscle density in older men and women. Neurobiol Aging. 2006;27: $1145-1154$

18. Inzitari M, Carlo A, Baldereschi M, et al. Risk and predictors of motorperformance decline in a normally functioning population-based sample of elderly subjects: the Italian Longitudinal Study on Aging. $J \mathrm{Am}$ Geriatr Soc. 2006;54:318-324.

19. Holzer SE, Camerota A, Martens L, Cuerdon T, Crystal P, Zagari M. Costs and duration of care for lower extremity ulcers in patients with diabetes. Clin Ther. 1998;20:169-181.

20. Caputo GM, Cavanagh PR, Ulbrecht JS, Gibbons GW, Karchmer AW. Assessment and management of foot disease in patients with diabetes. N Engl J Med. 1994;331:854-860.

21. Koski K, Luukinen H, Laippala P, Kivela SL. Risk factors for major injurious falls among the home-dwelling elderly by functional abilities. A prospective population-based study. Gerontology. 1998;44:232-238.

22. Schwartz AV, Hillier TA, Sellmeyer DE, et al. Older women with diabetes have a higher risk of falls: a prospective study. Diabetes Care. 2002;25:1749-1754.

23. Viswanathan V, Tilak P, Kumpatla S. Risk factors associated with the development of overt nephropathy in type 2 diabetes patients: a 12 -year observational study. Indian J Med Res. 2012;136(1):46-53.

24. Vinik AI, Strotmeyer ES, Nakave AA, Patel CV. Diabetic neuropathy in older adults. Clin Geriatr Med. 2008;24(3):407.

25. Valensi P, Giroux C, Seeboth-Ghalayini B, Attali JR. Diabetic peripheral neuropathy: effects of age, duration of diabetes, glycemic control, and vascular factors. J Diabetes Complications. 1997;11(1):27-34.
Clinical Interventions in Aging

\section{Publish your work in this journal}

Clinical Interventions in Aging is an international, peer-reviewed journal focusing on evidence-based reports on the value or lack thereof of treatments intended to prevent or delay the onset of maladaptive correlates of aging in human beings. This journal is indexed on PubMed Central, MedLine,

\section{Dovepress}

CAS, Scopus and the Elsevier Bibliographic databases. The manuscript management system is completely online and includes a very quick and fair peer-review system, which is all easy to use. Visit http://www.dovepress. com/testimonials.php to read real quotes from published authors. 